\title{
REDES NEURAIS CLASSE MODULAR APLICADAS NO RECONHECIMENTO DE CARACTERES MANUSCRITOS
}

\section{CLASS MODULAR NEURAL NETWORKS APPLIED IN RECOGNITION OF CHARACTER MANUSCRIPT}

Clariane Silva Menezes ${ }^{1}$; Leandro Luiz de Almeida ${ }^{2}$; Francisco Assis da Silva ${ }^{2}$; Mário Augusto Pazoti ${ }^{2}$; Almir Olivette Artero ${ }^{3}$

Discente da Faculdade de Informática da UNOESTE ${ }^{1}$; Docentes da Faculdade de Informática da UNOESTE ${ }^{2}$; Docente da Faculdade de Ciências e Tecnologia da UNESP ${ }^{2}$. E-mail chico@unoeste.br ${ }^{2}$.

RESUMO - O reconhecimento de caracteres manuscritos ainda é um grande desafio da área de visão computacional, devido principalmente à diversidade de estilos que as pessoas podem escrever, o que dificulta generalizar o problema. Além disso, existe também a dificuldade em definir os descritores que melhor caracterizam o caractere e construir sistemas OCR de alto desempenho. Este artigo apresenta um sistema de reconhecimento de caracteres manuscritos off-line, utilizando Redes Neurais Artificiais Classe Modular com o algoritmo clássico de treinamento backpropagation, além dos métodos utilizados para a extração de características. Apesar do treinamento dos classificadores neurais exigirem muito tempo de processamento e o reconhecimento das 62 classes de caracteres, que poucos trabalhos consideram, os resultados obtidos com os experimentos se mostram muito promissores, alcançando taxas de acerto acima de $90 \%$.

Palavras-chave: Reconhecimento de Padrões; Rede Neural Artificial; Processamento de Imagens; Sistemas OCR; Visão Computacional.

ABSTRACT - The handwritten character recognition is still a major challenge in the field of computer vision, primarily due to the diversity of styles that people can write, which makes it difficult to generalize the problem. In addition, there is also the difficulty in defining the descriptors that best characterize the character and build high performance OCR systems. This paper presents a system for recognizing handwritten characters offline, using Artificial Neural Networks Modular Class with classic backpropagation training algorithm, besides the methods used for feature extraction. Although training of neural classifiers require long processing and recognition of 62 classes of characters, few studies have considered the results obtained from the experiments are shown very promising, achieving hit rates above $90 \%$.

Keywords: Pattern Recognition; Artificial Neural Network; Image Processing; OCR Systems; Computer Vision. 


\section{INTRODUÇÃO}

O computador vem ganhando cada vez mais espaço na sociedade. Entretanto, isso não foi o suficiente para acabar com os documentos manuscritos. Por outro lado, conseguir automatizar 0 processo de digitalização, de forma que o conteúdo do documento seja disponibilizado automaticamente, facilitaria a leitura de cheques bancários, endereçamento de cartas ou mesmo formulários diversos (SILVA, 2006). Porém, apesar do surgimento de tantos avanços tecnológicos, fazer com que o computador simule a função humana de leitura tem sido um grande desafio para a área de visão computacional. Isso ocorre porque, além das pessoas possuírem estilos muito diferentes de escrever, o que pode impossibilitar até mesmo que outra pessoa consiga ler; há ainda a dificuldade em encontrar descritores eficientes para um conjunto de caracteres. Outra dificuldade está em aplicar melhorias nos métodos de reconhecimento off-line, a fim de construir um sistema OCR (Optical Character Recognition) de alto desempenho que otimize o reconhecimento de caracteres manuscritos.

Uma abordagem para solucionar esse problema é descrito na Figura 1. É uma abordagem para sistemas de reconhecimento off-line, em que os dados, nesse caso os caracteres, são obtidos de uma imagem completa, que é apresentada ao sistema para ser processada e reconhecida (CRUZ, 2008).

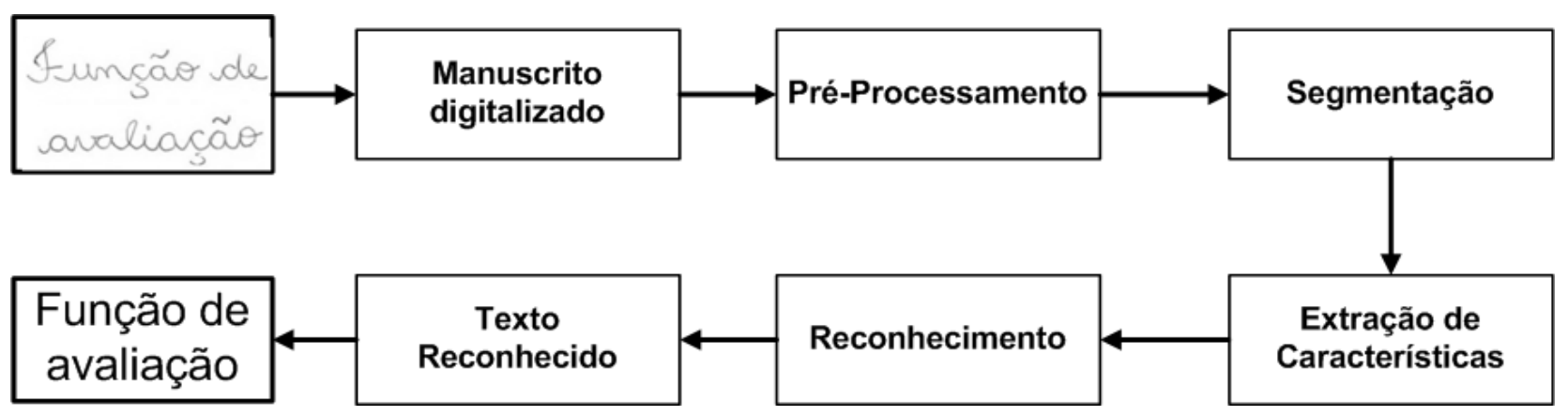

Figura 1. Sequência de execução para o reconhecimento de caracteres manuscritos. Fonte: Adaptado de Silva (2002).

Inicialmente, após a digitalização da imagem, é necessário fazer um préprocessamento nela para eliminar possíveis ruídos e realçar as características do padrão, e técnicas tais como: aumento de contraste, limiarização, binarização e afinamento; são comuns de serem utilizadas nesta etapa. As técnicas podem ser utilizadas antes ou depois da segmentação (SILVA, 2010). Em seguida, os caracteres são segmentados (separados) 
em letras para posterior análise (SILVA, 2010). A etapa de extração de características tem papel importante no sucesso do processo de reconhecimento, pois é nela que se definem os descritores que melhor caracterizarão o padrão apresentado. Existem inúmeras técnicas que podem ser utilizadas, a citar: matrizes de co-ocorrência (MIRANDA et al., 2013), medidas de distâncias borda-caracteres (MIRANDA et al., 2013), densidades regionais (CAMPESTRINI, 2000; MIRANDA et al., 2013; OSÓRIO, 1991) e pontos finais (CAMPESTRINI, 2000). Na etapa de reconhecimento, é comum utilizar técnicas de classificação supervisionada, na qual é realizada uma sessão de treinamento com apresentação de um conjunto de padrões de classes conhecidas, para que seja possível identificar novos padrões dessas classes (MIRANDA et al., 2013). As Redes Neurais Artificiais (RNAs) são comumente usadas nessa etapa, por se adaptarem a responder a um padrão específico durante o seu aprendizado (HAYKIN, 1994), além de terem uma precisão melhor e por requerer menos tempo de desenvolvimento (ZURADA, 1992). Isso também pode ser observado, pois nos trabalhos apresentados na Seção 2, a maioria teve resultados satisfatórios usando RNAs.

Este trabalho propõe um sistema de reconhecimento de caracteres manuscritos a partir de imagens de forma off-line, em que o reconhecimento fica por conta de duas RNAs MultiLayer Perceptron (MLP), sendo uma Convencional e uma Classe Modular. Além disso, para garantir melhores taxas de acerto na etapa de reconhecimento, foi adotado um conjunto de 54 atributos, obtido por meio das técnicas de extração de descritores que foram avaliadas por Miranda et al. (2013).

As demais seções deste artigo estão organizadas da seguinte maneira: na Seção 2 são apresentados trabalhos relacionados ao reconhecimento de caracteres; Na Seção 3 é apresentada a metodologia utilizada no desenvolvimento do trabalho; Na Seção 4 são apresentados os resultados e a análise de desempenho obtido a partir de experimentos. Por fim, a Seção 5 apresenta os comentários finais e trabalhos futuros.

\section{TRABALHOS RELACIONADOS}

Nesta seção são apresentados os trabalhos relacionados ao desenvolvimento deste projeto, que se referem à etapa de reconhecimento de caracteres manuscritos por meio de abordagens utilizando RNA.

No trabalho de Campestrini (2000) é utilizada a arquitetura convencional de RNA para reconhecer caracteres maiúsculos da fonte Courier New, não apresentando taxas de erro por causa da utilização de um ambiente controlado; enquanto que no trabalho de Aires (2005), também para reconhecer caracteres maiúsculos, é utilizado 
uma RNA Classe Modular baseada em regiões perceptivas, obtendo taxa de acerto de $84,15 \%$.

O trabalho de Oh e Suen (2002), propõe o conceito de classe modular utilizando RNAs MLP, em que cada classe (especialista) é responsável por reconhecer um padrão (caractere). E, para combinar a saída dos especialistas, é utilizada a técnica de voto. Os estudos incluem o reconhecimento de dígitos manuscritos (97,30\% de acertos), letras maiúsculas (91,11\% de acertos), pares de dígitos conectados $(75,18 \%$ de acertos) e caracteres do código postal koreano $(68,75 \%$ de acertos).

Já no trabalho de Kapp (2004), é utilizado uma RNA convencional e uma RNA Classe Modular, para reconhecer palavras manuscritas referentes aos meses do ano e valores por extenso de cheques bancários. A taxa de acerto para a RNA Convencional foi de $48,02 \%$ enquanto que para a classe modular foi de $52,18 \%$.

O trabalho de Silva (2006) utiliza um comitê de redes neurais para 0 reconhecimento de caracteres manuscritos, sendo que alguns caracteres foram agrupados em um único agente, sendo alcançada a taxa de acertos de $93,61 \%$.

O trabalho de Silva (2010) utilizou o reconhecimento de palavras manuscritas para o problema de classificação de meses, utilizando para isso duas arquiteturas: RNA MLP e uma Support Vector Machine (SVM) e duas formas de extração de características: utilizando Edge Maps e Zonas. As taxas de acertos obtidas para as RNAs MLP e SVM foram, respectivamente, $86,31 \%$ e $86,11 \%$ utilizando a extração de Edge Maps; e $86,31 \%$ e $86,11 \%$ utilizando a extração em Zonas.

A contribuição do trabalho de Miranda et al. (2013) foi discriminar as características dos caracteres maiúsculos, minúsculos e dígitos de forma mais precisa, sendo baseadas em contagem de pixels, sendo o tempo processamento muito baixo. Para o reconhecimento dos caracteres, foi utilizada uma abordagem baseada nos valores máximos e mínimos de cada atributo extraído, para cada tipo de caractere, obtendo taxa de acertos de $89,46 \%$; e uma RNA MLP, que obteve taxa de acertos de $94,46 \%$.

\section{METODOLOGIA}

A metodologia aplicada nesse trabalho para o reconhecimento de caracteres manuscritos, sendo eles maiúsculos, minúsculos ou dígitos; é apresentada na Figura 2.

O detalhamento do funcionamento de cada uma das etapas, bem como as técnicas utilizadas, é apresentado a seguir. 


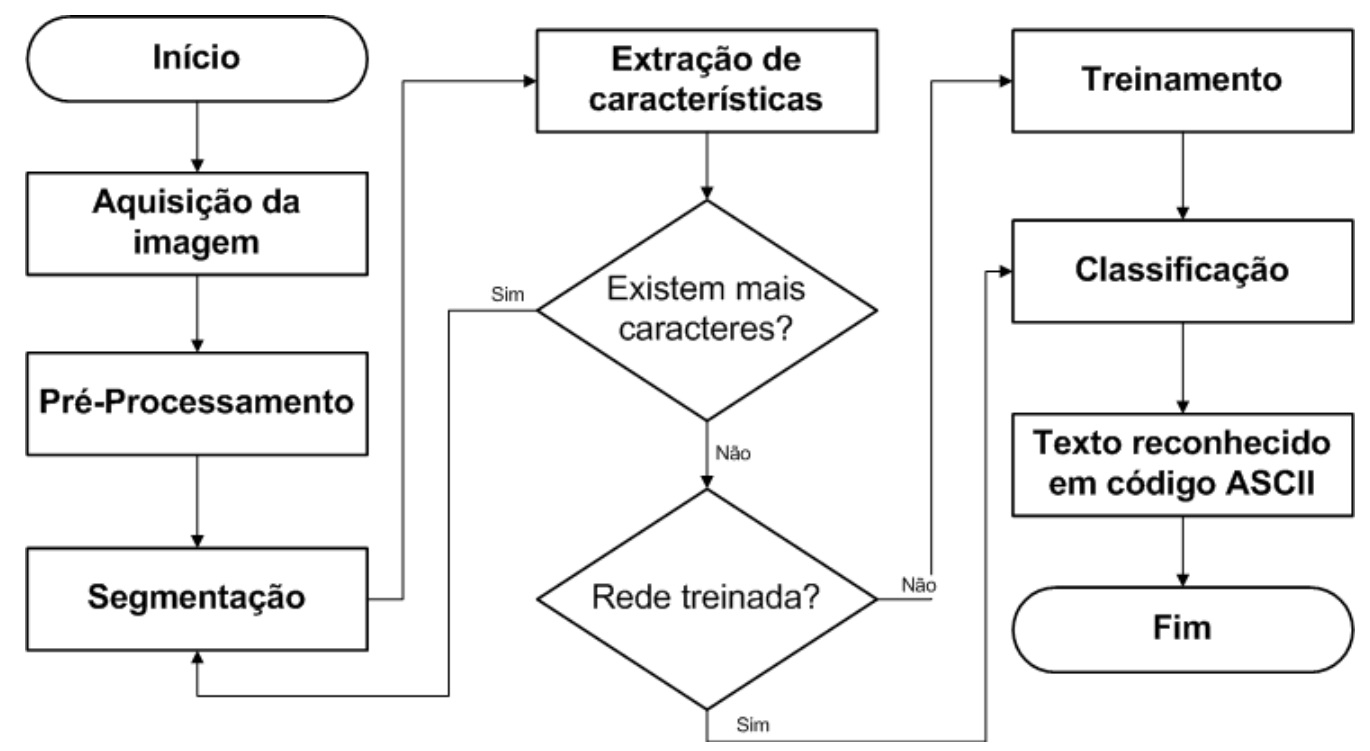

Figura 2. Metodologia para o treinamento e reconhecimento.

\section{Aquisição da imagem}

A captura da imagem que contém os caracteres que se deseja fazer 0 reconhecimento, é feita por um dispositivo de digitalização, como um scanner, e a imagem obtida é armazenada na memória do computador.

\section{Pré-Processamento}

No pré-processamento, é realizado o tratamento da imagem, padronizando a sua aparência com a aplicação de técnicas como luminância, binarização e afinamento. A primeira técnica utilizada, luminância (GONZALEZ; WOODS, 2010), aplica a equação

(1) para deixar a imagem em tons de cinza.

Luminância $=0.299 R+0.587 G+0.114 B$

O próximo passo é deixar a imagem binária (em preto e branco). Utilizando a técnica de binarização de Otsu (1979), é encontrado um limiar para a imagem, e por esse limiar os pixels são comparados para definir se eles são brancos (representando o papel) ou pretos (representando a tinta no papel).

Ao final, aplica-se a operação de afinamento (thinning) nos caracteres, reduzindo a sua forma para uma versão simplificada, mas que retém as características originais (PLOTZE; PAZOTI; BRUNO, 2005). Para isso, é utilizado o algoritmo de Zhang e Suen (GONZALEZ; WOODS, 2010).

\section{Segmentação}

Essa etapa consiste em separar os caracteres da imagem para serem utilizados em etapas posteriores, como a extração de 
Algoritmo para segmentação de caracteres

1. Inicialização. Cria-se uma lista que mapeia os pixels pretos em y (linha por linha).

2. Delimitando linhas. Procura-se a incidência da linha com o primeiro pixel preto e a que antecede um pixel branco.

3. Cria-se uma lista que mapeia os pixels em x, de acordo com a limitação do passo 2 .

4. Delimitando colunas. Procura-se a incidência da coluna com o primeiro pixel preto e a que antecede um pixel branco.

5. Tendo o caractere sido delimitado, deixa-se uma borda no tamanho de 1 pixel em volta do caractere.

6. Extrair caracteristicas. É extraída as características do caractere que foi encontrado.

7. Repetir o passo 2 até segmentar todos os caracteres da imagem.

Figura 3. Algoritmo para segmentação dos caracteres.

\section{Extração de características}

Nessa etapa, são representadas numericamente as características presentes no caractere segmentado. É necessário capturar as informações que sejam relevantes para a etapa de classificação, e, para isso, são utilizadas contagens de pixels de caractere e fundo (matrizes de coocorrências, medidas de distâncias bordacaractere, densidades regionais e pontos finais).

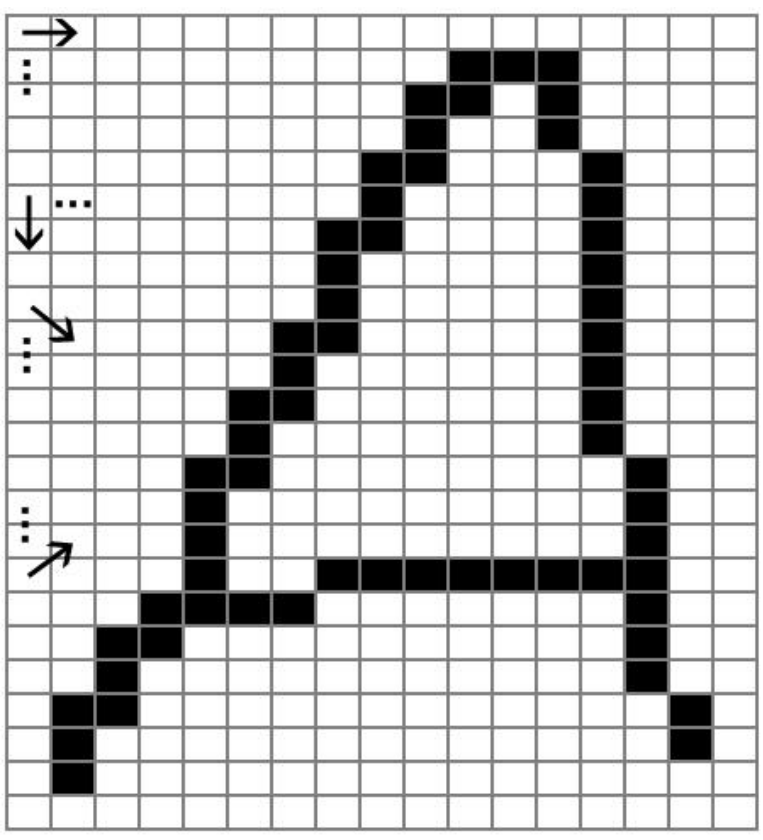

(a)

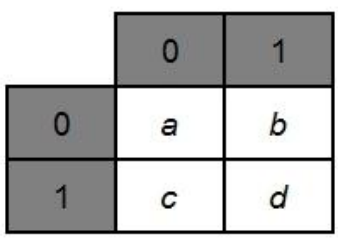

(b)

Figura 4. a) As quatro direções usadas para analisar as transições dos pixels e b) A matriz de coocorrência que é gerada para cada uma das direções, com os valores de frequência $a, b, c$ e $d$.

A matriz de co-ocorrência analisa a transição na cor de dois pixels, sendo um chamado de pixel referência e o outro de pixel vizinho. Para isso, as matrizes são construídas usando operadores de posição: $\mathrm{P} 1$ = "pixel à direita", P2 = "pixel abaixo", P3 
= "pixel à direita e acima" e P4 = "pixel à direita e abaixo" (MIRANDA et al., 2013), como ilustrado na Figura 4a. Como as imagens são binárias, são obtidas matrizes $2 \times 2$, que registram as frequências encontradas nas transições possíveis entre os vizinhos: 00, 01, 10 e 11, como ilustrado na Figura 4b. Por serem utilizadas quatro matrizes, e cada matriz gera quatro valores, são obtidos 16 atributos com essa técnica para comporem o vetor de características.

A medida da distância borda-caractere é efetuada uma contagem, a partir da borda, dos pixels de fundo (brancos) que antecedem o pixel do caractere (preto), nas oito direções $(\rightarrow, \leftarrow, \downarrow, \uparrow, \searrow, \nearrow, \swarrow, \nwarrow)$ (MIRANDA et al., 2013), gerando 8 atributos (Figura 5). Utilizando a mesma distância bordacaractere, porém com faixas sobrepostas, de modo a minimizar as diferenças de contagens de uma região para outra (MIRANDA et al., 2013), são utilizadas cinco faixas na horizontal e na vertical, obtendo mais 20 atributos. 0 tamanho da faixa utilizada é de 3 pixels.

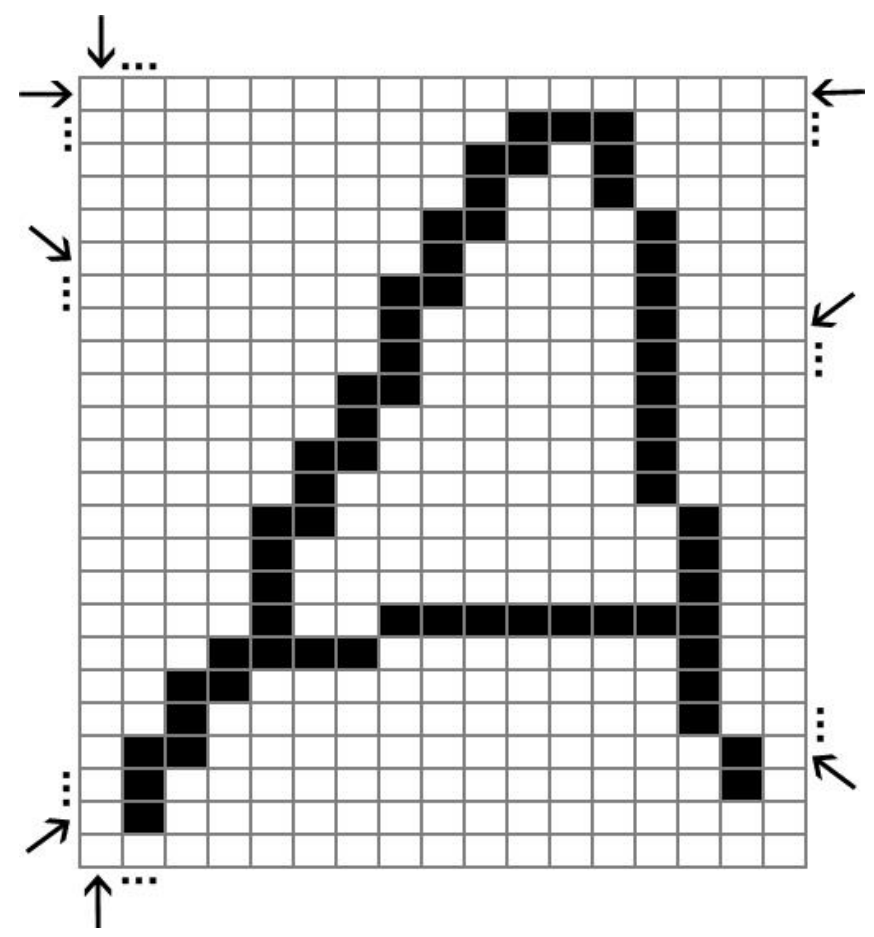

Figura 5. As oito direções usadas para medir as distâncias borda-caractere.

A densidade regional da imagem é obtida dividindo a imagem em 9 regiões, e calculando a quantidade de pixels pretos existentes nessas 9 regiões (CAMPESTRINI, 2000; OSÓRIO, 1991). Na Figura 6 é mostrado um caractere ' $A$ ' com as densidades por regiões. Nesta técnica são gerados 9 atributos.

A contagem de pontos finais é feita contando os pixels pretos conexos na versão delgada da imagem como, por exemplo, a letra ' $A$ ', que tem dois pontos finais 
localizados na base, e a letra "O", que tem um ponto final (CAMPESTRINI, 2000). Nesta técnica é gerado 1 atributo.

Desse modo, ao todo são extraídos 54 atributos para descrever os 62 caracteres, sendo 26 caracteres maiúsculos $(A, \ldots, Z), 26$ caracteres minúsculos $(a, \ldots, z)$ e 10 dígitos $(0, \ldots, 9)$.

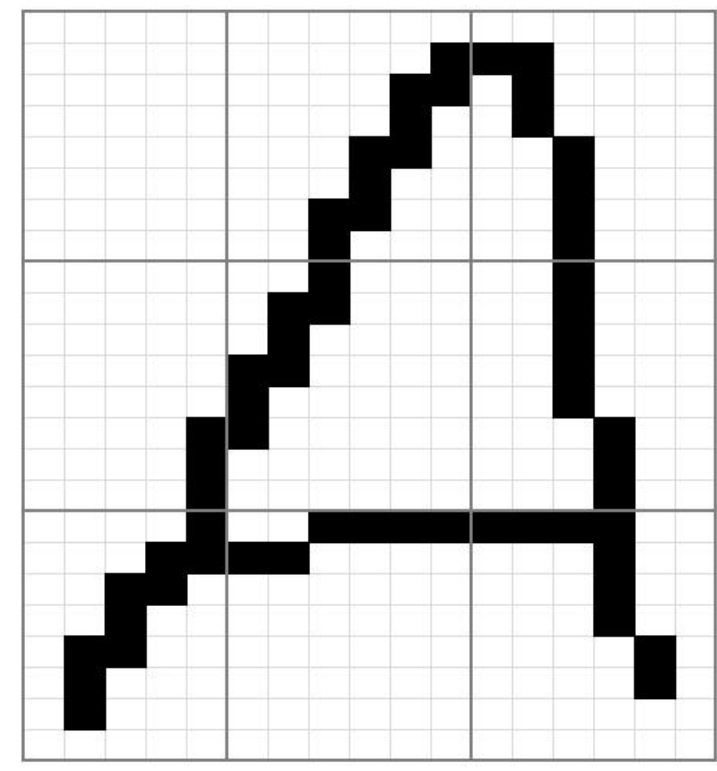

(a)

\begin{tabular}{|c|c|c|}
\hline 0 & 10 & 8 \\
\hline 3 & 8 & 8 \\
\hline 10 & 6 & 9 \\
\hline
\end{tabular}

(b)

Figura 6. a) Caractere ' $A$ ' dividido em 9 regiões e b) Matriz com as densidades de cada uma das 9 regiões do caractere ' $A$ '.

\section{Treinamento}

Para a etapa de treinamento, foram adotadas duas abordagens de RNA: uma Convencional e uma Classe Modular.

A abordagem Convencional utiliza o Perceptron de Múltiplas Camadas (MLP), possuindo uma camada de entrada com 54 neurônios, uma camada oculta com 58 neurônios e uma camada de saída com 62 neurônios, representando as 62 classes de caracteres (maiúsculos, minúsculos e dígitos). O neurônio vencedor é determinado pela classe (caractere) que tiver a maior saída para o exemplo de entrada.
Já a segunda abordagem, a Classe Modular (Figura 7b), ao contrário da abordagem Convencional, que utiliza uma RNA para classificar todos os caracteres, é utilizada uma RNA para classificar cada um dos caracteres, totalizando 62 redes. Cada uma dessas redes, chamadas de especialista, tem o seu treinamento independente das outras. Cada uma dessas redes especialistas possui 54 neurônios na camada de entrada, 28 neurônios na camada oculta e 2 neurônios na camada de saída (pertence ou não pertence), e pode ser analisada na Figura 7a. Para determinar a saída da rede, primeiro é necessário escolher o neurônio vencedor de 
cada especialista. Feito isso para todos os especialistas, as saídas são organizadas de forma decrescente em um ranking, sendo que o neurônio vencedor (especialista) será o da maior saída. Porém, como cada

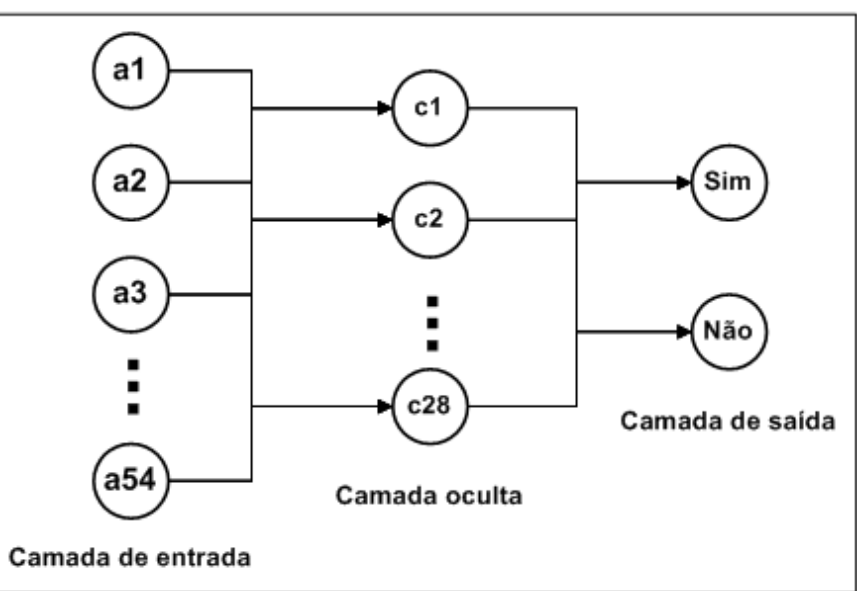

(a) (b)

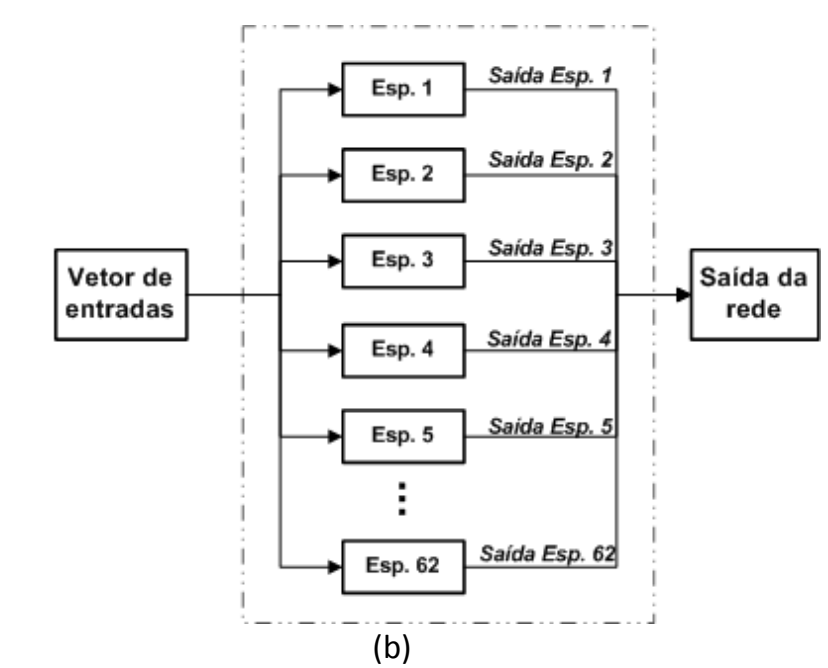

Figura 7. a) Núcleo das redes que constituem a RNA, b) Estrutura da RNA Classe Modular.
Para ambas as abordagens foi utilizado o algoritmo de aprendizagem backpropagation, com taxa de aprendizagem igual a 0.55, função de transferência logística e 1500 iterações para convergência das RNAs. Como RNAs são aversas a zeros, já que as ligações entre os neurônios são basicamente multiplicações; para as primitivas que não foram encontradas (onde o valor seja zero), atribui-se o valor 0,001 (AIRES, 2005).

\section{Classificação e texto reconhecido em código ASCII}

Na etapa de classificação, um novo padrão das classes utilizadas no treinamento é apresentado às RNAs para ser classificado. especialista pode ser responsável ou não pela resposta do padrão apresentado, pode acontecer de não ter nenhuma resposta para o padrão.
É escolhido o neurônio vencedor da RNA, tanto da Convencional como da Classe Modular, e o resultado é apresentado em código da tabela ASCII.

\section{EXPERIMENTOS}

Esta seção apresenta os experimentos usando as metodologias propostas neste trabalho, bem como a análise de desempenho. A fim de estabelecer um comparativo dos resultados obtidos com esse trabalho, foram utilizadas as imagens dos experimentos do trabalho de Miranda et al. (2013).

Para o Experimento I foi utilizada no treinamento uma imagem contendo 35 repetições diferentes dos 62 caracteres $(A, \ldots$, $Z, a, \ldots, z, 0, \ldots, 9)$, totalizando 2170 registros; 
e para teste outra imagem contendo 15 caracteres, totalizando 930 registros repetições diferentes dos mesmos 62 (Figura 8).

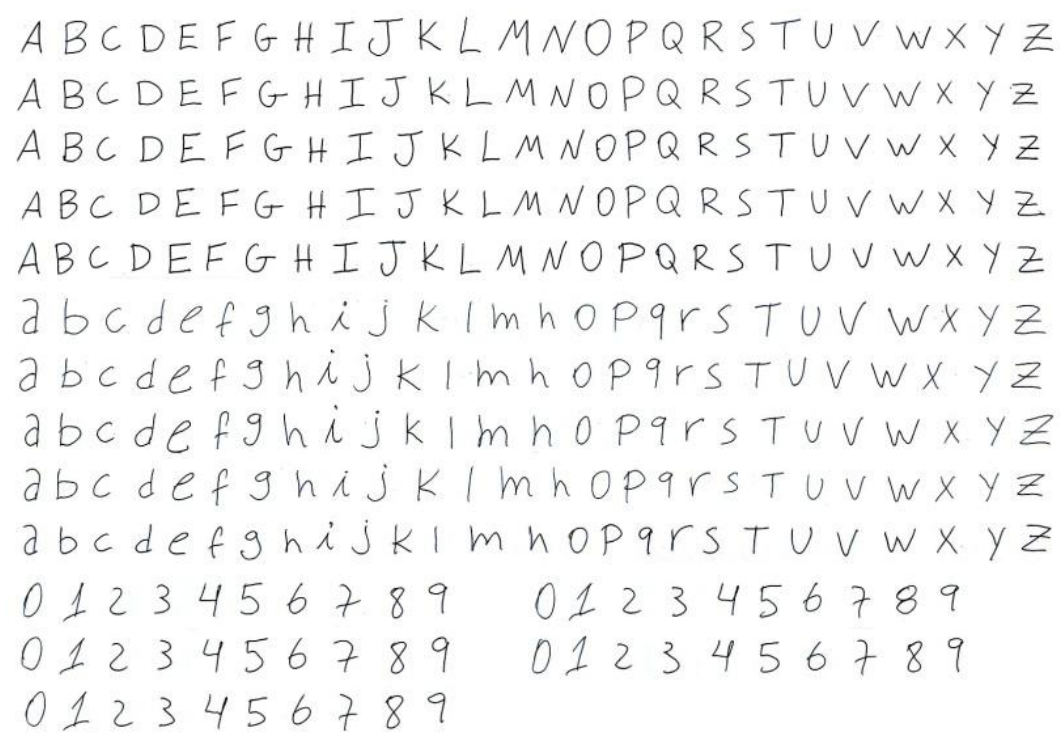

Figura 8. Conjunto de caracteres.

Fonte: Miranda et al. (2013)

Para o Experimento II foi utilizada para treinamento uma imagem contendo 30 fontes diferentes, totalizando 300 registros, e para teste outras 10 fontes diferentes, totalizando 100 registros (Figura 9).
E para o Experimento III foi utilizado o mesmo conjunto de treinamento e teste do Experimento I, porém separando as classes de caracteres em maiúsculos, minúsculos e dígitos.

\begin{tabular}{|ll|}
\hline $\mathbf{0 1 2 3 4 5 6 7 8 9}$ & 0123456789 \\
0123456789 & 0123456789 \\
$\mathbf{0 1 2 3 4 5 6 7 8 9}$ & $\mathbf{0 1 2 3 4 5 6 7 8 9}$ \\
$\mathbf{0 1 2 3 4 5 6 7 8 9}$ & $\mathbf{0 1 2 3 4 5 6 7 8 9}$ \\
$\mathbf{0 1 2 3 4 5 6 7 8 9}$ & 0123456789 \\
$\mathbf{0 1 2 3 4 5 6 7 8 9}$ & 0123456789 \\
0123456789 & 0123456789 \\
0123456789 & 0123456789 \\
0123456789 & 0123456789 \\
0123456789 & 0123456789 \\
$\mathbf{0 1 2 3 4 5 6 7 8 9}$ & $\mathbf{0 1 2 3 4 5 6 7 8 9}$ \\
$\mathbf{0 1 2 3 4 5 6 7 8 9}$ & 0123456789 \\
0123456789 & $\mathbf{0 1} 23456789$ \\
$\mathbf{0 1 2 3 4 5 6 7 8 9}$ & 0123456789 \\
0123456789 & 0123456789 \\
\hline
\end{tabular}

(a)

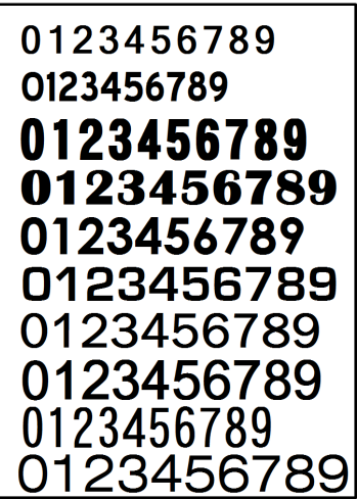

(b)

Figura 9. Conjunto de caracteres impressos: a) Conjunto de treinamento, b) Conjunto de teste. Fonte: Miranda et al. (2013). 


\section{Experimento I}

A RNA Classe Modular obteve uma taxa de acerto de 93,33\%, identificando corretamente 868 dos 930 caracteres, enquanto que a RNA Convencional obteve $94,84 \%$, identificando corretamente 882 caracteres. A Figura 10 apresenta os resultados das duas abordagens, separando os acertos nas três categorias de caracteres: maiúsculos, minúsculos e dígitos. $\mathrm{E}$ a abordagem de máximos e mínimos de
Miranda et al. (2013) obteve taxa de acerto de $89,25 \%$, reconhecendo 830 caracteres.

Experimento II

Tanto a RNA Classe Modular e a Convencional obtiveram taxa de acerto de 100\%, acertando os 100 caracteres. Já a abordagem de máximos e mínimos de Miranda et al. (2013) obteve taxa de acerto de $94 \%$, reconhecendo 94 dos 100 caracteres.

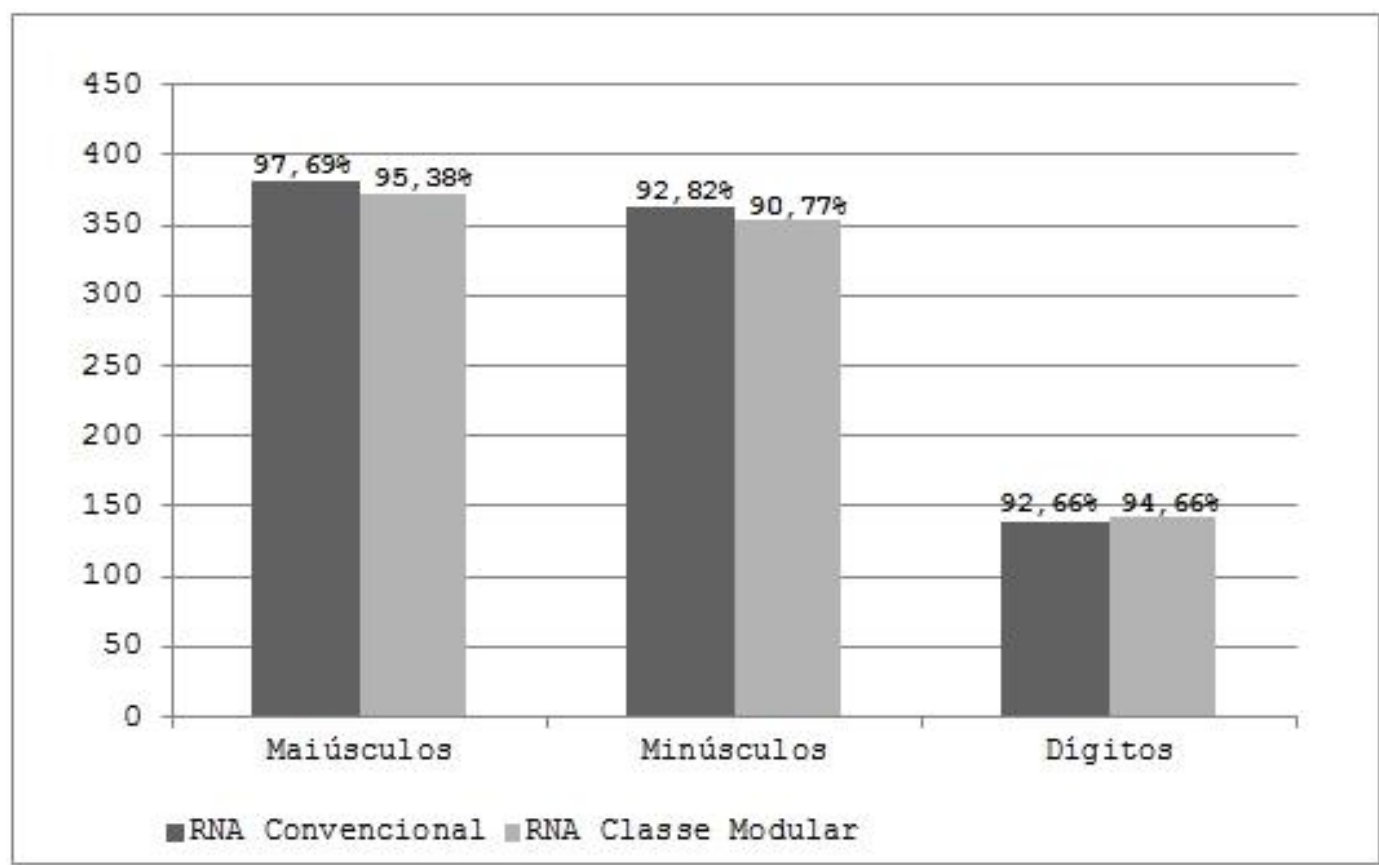

Figura 10. Resultados do Experimento I, identificando a porcentagem de acertos que cada uma das abordagens teve para cada tipo de caractere (maiúsculos, minúsculos e dígitos), que compõe o resultado final de $94,84 \%$ para a RNA Convencional e de 93,33\% para a RNA Classe Modular.

\section{Experimento III}

A RNA Convencional obteve taxa de acerto de $99,74 \%$ para o conjunto de caracteres maiúsculos, identificando corretamente 389 caracteres de 390, de $98,20 \%$ para o conjunto de caracteres minúsculos, identificando corretamente 383 caracteres de 390 e de $100 \%$ para o conjunto de dígitos, identificando corretamente os 150 caracteres apresentados. Já a RNA Classe Modular obteve taxa de acerto de $98,20 \%$ para o conjunto de caracteres maiúsculos, identificando corretamente 383 caracteres de 390 , de $96,41 \%$ para o conjunto de caracteres minúsculos, identificando corretamente 376 caracteres de 390 e de 
99,33\% para o conjunto de dígitos, identificando corretamente 149 caracteres dos 150 apresentados. A Figura 11 apresenta o resultado das duas abordagens, com o treinamento sendo separado em caracteres maiúsculos, minúsculos e dígitos.

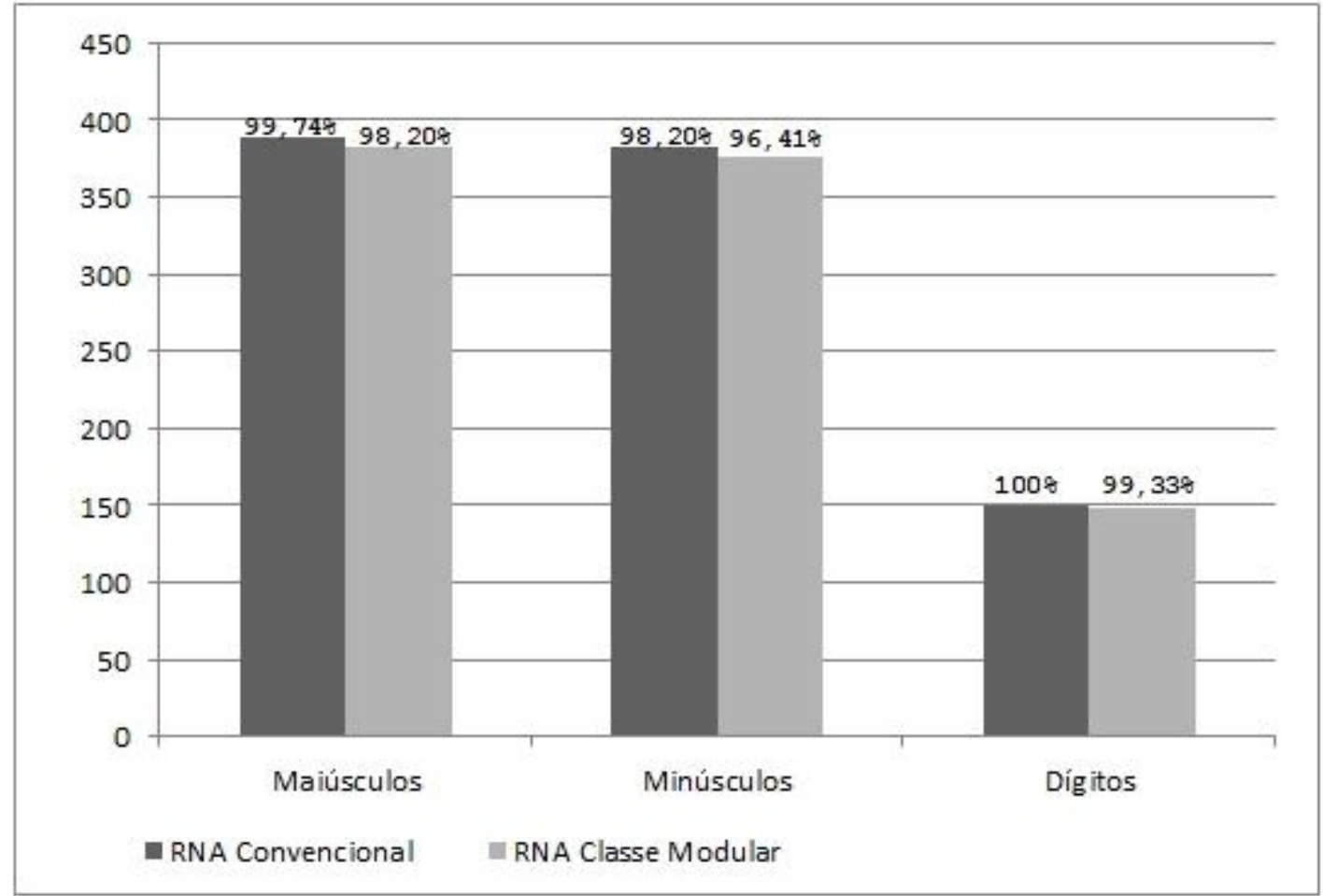

Figura 11. Resultados do Experimento III, onde o conjunto de treinamento foi dividido em caracteres maiúsculos, minúsculos e dígitos.

\section{Resumo dos resultados}

O resumo dos resultados dos experimentos, com taxas de acerto e de erro,

Tabela 1. Resumo dos resultados dos experimentos para a abordagem Convencional.

\begin{tabular}{|c|c|c|}
\cline { 2 - 3 } \multicolumn{1}{c|}{} & Acertos & Erros \\
\hline Experimento I & $882(94,84 \%)$ & $48(5,16 \%)$ \\
\hline Experimento II & $100(100 \%)$ & $0(0 \%)$ \\
\hline $\begin{array}{c}\text { Experimento III } \\
\text { (Maiúsculos) }\end{array}$ & $389(99,74 \%)$ & $1(0,26 \%)$ \\
\hline $\begin{array}{c}\text { Experimento III } \\
\text { (Minúsculos) }\end{array}$ & $383(98,20 \%)$ & $7(1,79 \%)$ \\
\hline $\begin{array}{c}\text { Experimento III } \\
\text { (Dígitos) }\end{array}$ & $150(100 \%)$ & $0(0 \%)$ \\
\hline
\end{tabular}

é apresentado nas Tabelas 1 e 2, para a abordagem Convencional e Classe Modular, respectivamente.

Tabela 2. Resumo dos resultados dos experimentos para a abordagem Classe Modular.

\begin{tabular}{|c|c|c|}
\cline { 2 - 3 } \multicolumn{1}{c|}{} & Acertos & Erros \\
\hline Experimento I & $868(93,33 \%)$ & $62(6,66 \%)$ \\
\hline Experimento II & $100(100 \%)$ & $0(0 \%)$ \\
\hline $\begin{array}{c}\text { Experimento III } \\
\text { (Maiúsculos) }\end{array}$ & $383(98,20 \%)$ & $7(1,79 \%)$ \\
\hline $\begin{array}{c}\text { Experimento III } \\
\text { (Minúsculos) }\end{array}$ & $376(96,41 \%)$ & $14(3,59 \%)$ \\
\hline $\begin{array}{c}\text { Experimento III } \\
\text { (Dígitos) }\end{array}$ & $149(99,33 \%)$ & $1(0,66 \%)$ \\
\hline
\end{tabular}


Análise de desempenho

O tempo médio no processamento da extração dos 54 atributos do conjunto de caracteres ilustrados na Figura 8 é de 56,7100997 segundos, utilizando uma máquina com processador Intel Core i3-3220, com clock de $3.30 \mathrm{GHz}$ e $4 \mathrm{~GB}$ de memória RAM.

O tempo de processamento para a etapa de treinamento da RNA Convencional foi de 54 minutos e 15 segundos, enquanto que para a RNA Classe Modular foi de 6 horas e 12 minutos, ambas utilizando o conjunto da Figura 8, com 2170 registros (35 repetições de cada um dos 62 caracteres).

O tempo médio para 0 reconhecimento por caractere é de 0,001109 segundos para a RNA Convencional e de 0,014944 segundos para a RNA Classe Modular.

\section{CONSIDERAÇÕES FINAIS}

O processo de reconhecer caracteres manuscritos ainda é bastante dificultoso devido aos problemas já levantados na Introdução (Seção 1). Entretanto, um sistema que obtenha sucesso nessa tarefa possui um campo de aplicação em potencial, como a leitura automática de cheques bancários, endereçamento de cartas, formulários diversos, entre outros.

E dos trabalhos investigados (Seção 2), poucos autores consideram o reconhecimento das 62 classes de caracteres (26 caracteres maiúsculos, 26 caracteres minúsculos e 10 dígitos). Sendo assim, apesar da fase de treinamento dos classificadores exigir muito tempo de processamento, os resultados obtidos com os experimentos realizados neste trabalho, quando comparados aos resultados apresentados pelos trabalhos encontrados na literatura, mostram-se bastante promissores. Além disso, as altas taxas de acertos indicam não só a qualidade da etapa de treinamento, mas também das etapas anteriores, como a extração de características, que é considerada crucial para o sucesso de um sistema de reconhecimento de caracteres.

Futuros trabalhos podem ser
desenvolvidos aplicando técnicas de
segmentação para caracteres conectados; com inclusão de técnicas de extração de características que maximizem a capacidade de reconhecimento dos classificadores; reconhecendo caracteres especiais, como caracteres com acentuação e símbolos de pontuação; diminuir o tempo de processamento das RNAs, e tentar a combinação do classificador neural com lógica fuzzy. Também é de grande valia o aprimoramento deste trabalho para escritas cursivas e com caracteres conectados. 


\section{REFERÊNCIAS}

AIRES, S. B. K. Reconhecimento de caracteres manuscritos baseado em Regiões Perceptivas. 2005. 97 f. Dissertação (Mestrado) - Pontifícia Universidade Católica do Paraná, Curitiba.

CAMPESTRINI, M. R. Protótipo de um sistema de reconhecimento de caracteres baseado em redes neurais. 2000. $45 \mathrm{f}$. Monografia (Graduação) - Universidade Regional de Blumenau, Blumenau.

CRUZ, R. M. O. Análise de técnicas de extração de características para 0 reconhecimento de dígitos manuscritos. 2008. 37 f. Monografia (Graduação) Universidade Federal de Pernambuco, Pernambuco.

GONZALEZ, R. C.; WOODS, R. E. Processamento digital de imagens. 3. ed. São Paulo: Pearson Prentice Hall, 2010.

HAYKIN, S. Neural Networks: A Comprehensive Foundation. 2. Ed. Upper Saddle River: Prentice Hall, 1994.

KAPP, M. N. Reconhecimento de palavras manuscritas utilizando redes neurais artificiais. 2004. 116 f. Dissertação (Mestrado) - Pontifícia Universidade Católica do Paraná, Curitiba.

MIRANDA, R. A. R. et al. Handwritten character recognition based on frequency, character-edge distances and densities. In: WORKSHOP DE VISÃO COMPUTACIONAL, FGV, Rio de Janeiro, 2013.

$\mathrm{OH}$, I.; SUEN, C. Y. A class-modular feedforward neural network for handwriting recognition. Pattern Recognition, v.35, p. 229-244, 2002.

OSÓRIO, F. S. Um estudo sobre o reconhecimento de caracteres através de redes neurais. 1991. 302 f. Dissertação
(Mestrado) - Universidade Federal do Rio Grande do Sul, Porto Alegre.

OTSU, N. A threshold selection method from gray-level histograms. IEEE Transactions on Systems, Man, and Cybernetics, p. 62-66, 1979.

PLOTZE, R. O.; PAZOTI, M. A.; BRUNO, O. M. Técnicas de afinamento aplicadas no reconhecimento de caracteres impressos. In: I Workshop de Visão Computacional, 1., 2005, UNIMEP, Anais... Piracicaba, 2005, p. 56-59.

SILVA, E. Reconhecimento Inteligente de Caracteres Manuscritos. 2002. 173 f. Dissertação (Mestrado) - Instituto Militar de Engenharia, Rio de Janeiro.

SILVA, E. V. Sistema de reconhecimento de palavras manuscritas em domínios restritos. 2010. 54 f. Monografia (Graduação) Universidade Federal de Pernambuco, Recife.

SILVA, V. S. R. Um comitê de Redes Neurais para Reconhecimento de Caracteres Manuscritos. 2006. 121 f. Dissertação (Mestrado) - Universidade Federal Do Rio de Janeiro, Rio de Janeiro.

ZURADA, J. M. Introduction to artificial neural systems. St. Paul: West Publishing, 1992. 